University of Wollongong

Research Online

Faculty of Engineering and Information

Faculty of Engineering and Information

Sciences - Papers: Part A

Sciences

$1-1-2012$

\title{
Axial and flexural performance of square RC columns wrapped with CFRP under eccentric loading
}

Muhammad N. S Hadi

University of Wollongong, mhadi@uow.edu.au

Ida Bagus Rai Widiarsa

University of Wollongong, ibrw943@uowmail.edu.au

Follow this and additional works at: https://ro.uow.edu.au/eispapers

Research Online is the open access institutional repository for the University of Wollongong. For further information contact the UOW Library: research-pubs@uow.edu.au 


\title{
Axial and flexural performance of square RC columns wrapped with CFRP under eccentric loading
}

\author{
Abstract \\ The majority of studies on fiber-reinforced-polymer (FRP) strengthened concrete columns deal with \\ columns of a circular cross section. However, most concrete columns in the field have square or \\ rectangular cross sections and resist eccentric loads. This paper presents the results of an experimental \\ study on the performance of carbon-fiber-reinforced-polymer (CFRP) wrapped square reinforced concrete \\ (RC) columns under eccentric loading. The influence of the number of CFRP layers, the magnitude of \\ eccentricity, and the presence of vertical CFRP straps were investigated by testing 16 specimens. The \\ specimens had the dimensions $200 \times 200 \times 800 \mathrm{~mm}$ and round corners with a radius of $34 \mathrm{~mm}$. Twelve \\ specimens were tested as columns and four specimens as beams. The results of this study showed that \\ CFRP wrapping enhanced the load-carrying capacity and ductility of the columns under eccentric loading. \\ Furthermore, the application of the vertical CFRP straps significantly improved the performance of the \\ columns with large eccentricity
}

\section{Keywords}

cfrp, under, wrapped, columns, rc, square, performance, eccentric, flexural, axial, loading

\section{Publication Details}

Hadi, M. N. S. \& Widiarsa, I. (2012). Axial and flexural performance of square RC columns wrapped with CFRP under eccentric loading. Journal of Composites for Construction, 16 (6), 640-649. 


\title{
Axial and Flexural Performance of Square RC Columns Wrapped with CFRP under Eccentric Loading
}

\author{
Muhammad N. S. Hadi, M.ASCE${ }^{1}$; and Ida Bagus Rai Widiarsa²
}

\begin{abstract}
The majority of studies on fiber-reinforced-polymer (FRP) strengthened concrete columns deal with columns of a circular cross section. However, most concrete columns in the field have square or rectangular cross sections and resist eccentric loads. This paper presents the results of an experimental study on the performance of carbon-fiber-reinforced-polymer (CFRP) wrapped square reinforced concrete (RC) columns under eccentric loading. The influence of the number of CFRP layers, the magnitude of eccentricity, and the presence of vertical CFRP straps were investigated by testing 16 specimens. The specimens had the dimensions $200 \times 200 \times 800 \mathrm{~mm}$ and round corners with a radius of $34 \mathrm{~mm}$. Twelve specimens were tested as columns and four specimens as beams. The results of this study showed that CFRP wrapping enhanced the load-carrying capacity and ductility of the columns under eccentric loading. Furthermore, the application of the vertical CFRP straps significantly improved the performance of the columns with large eccentricity. DOI: 10.1061/(ASCE)CC .1943-5614.0000301. () 2012 American Society of Civil Engineers.
\end{abstract}

CE Database subject headings: Fiber reinforced polymer; Reinforced concrete; Concrete columns; Eccentric loads; Ductility.

Author keywords: CFRP; Square reinforced concrete columns; Eccentric loading; Ductility.

\section{Introduction}

High-strength concrete (HSC) has been used widely in civil construction projects due to its high compressive strength and elastic modulus. The use of HSC instead of normal-strength concrete (NSC) would reduce significantly member size and material consumption. HSC members behave differently than those made of NSC; HSC is more brittle than NSC. The failure of a HSC member is more explosive and sudden. A review of the literature shows that the majority of studies on fiber-reinforced-polymer (FRP) confined concrete columns investigated columns with NSC (e.g., Teng et al. 2002). Only a few studies investigated FRP confined columns with HSC (Li and Hadi 2003; Hadi 2007b; Eid et al. 2009).

The use of FRP composites for strengthening reinforced concrete members has been investigated experimentally by many researchers, and FRP has been applied in construction. Strengthening reinforced concrete columns using FRP composites is preferred to using other materials like steel due to the high strength-to-weight ratio and high corrosion resistance of FRP composites. Several investigations on FRP-strengthened concrete columns have been undertaken over the years. Most of these studies investigated the behavior of columns under concentric loads (Kumutha et al. 2007; Wang and Wu 2008; Lam and Teng 2002; Teng and Lam 2004; Rousakis et al. 2007), whereas only a few studies presented

\footnotetext{
${ }^{1}$ Associate Professor, School of Civil, Mining and Environmental Engineering, Univ. of Wollongong, Wollongong NSW 2522, Australia (corresponding author). E-mail: mhadi@uow.edu.au

${ }^{2}$ Lecturer, Dept. of Civil Engineering, Univ. of Udayana, Bali 80361, Indonesia; presently, Ph.D. Scholar at the School of Civil, Mining and Environmental Engineering, Univ. of Wollongong, Wollongong NSW 2522, Australia. E-mail: ibrw943@uowmail.edu.au

Note. This manuscript was submitted on November 20, 2011; approved on April 24, 2012; published online on April 26, 2012. Discussion period open until May 1, 2013; separate discussions must be submitted for individual papers. This paper is part of the Journal of Composites for Construction, Vol. 16, No. 6, December 1, 2012. (C) ASCE, ISSN 1090-0268/ 2012/6-640-649/\$25.00.
}

investigations of columns under eccentric loads. Consideration of applying eccentric loads was undertaken due to the reality that most columns in the field are loaded under a combination of axial compression load and bending moment. Bending moment always exists in a column, even though in columns nominally carrying only axial compression load, bending moment is introduced by unintentional load eccentricities and by out-of-straightness of the constructed column (Warner et al. 2007).

The effect of applying eccentric loads on FRP-strengthened concrete columns has been studied by a few researchers. Other than the magnitude of eccentricities, the shape of column cross section is an important factor that influences the confining behavior of FRP-strengthened concrete columns. Some researchers have investigated FRP-strengthened concrete columns under eccentric loads, focusing mostly on columns having a circular cross section ( $\mathrm{Li}$ and Hadi 2003; Hadi 2006a, b, 2007a, b; Bisby and Ranger 2010). Although most concrete columns in the field have square or rectangular cross sections rather than circular ones and may also resist eccentric loads, only a few investigations have studied concrete columns with square or rectangular cross sections (Parvin and Wang 2001; Maaddawy 2009). Both of these studies tested small-scale square concrete columns constructed with normal strength concrete. Columns tested by Parvin and Wang (2001) had no internal reinforcement and were wrapped with no layer, one layer, or two layers of CFRP. The columns were tested under concentric and eccentric loads. Columns tested by Maaddawy (2009) had no round corners but had end corbels. The columns were unwrapped, fully wrapped, and partially wrapped with CFRP and were tested eccentrically.

Consequently, research on FRP-strengthened square or rectangular HSC columns under eccentric loads must still be undertaken to understand their behavior and performance. This paper is directed toward this purpose. Parameters investigated in this study include the magnitude of eccentricity and the number of FRP layers. Three different eccentricities-0, 25, and $50 \mathrm{~mm}$-were investigated. In relation to the number of FRP layers, unwrapped columns, columns wrapped with one layer, and columns wrapped 
with three layers of CFRP were tested. Due to the significant effect of longitudinal fiber in eccentric loading (Chaallal and Shahawy 2000; Hadi 2007a), one layer of CFRP straps was applied longitudinally in combination with two layers of CFRP wrapped circumferentially.

\section{Experimental Program}

The experimental program consisted in testing a total of $16 \mathrm{RC}$ specimens, of which 12 were tested under compression loading and four under flexural loading. All specimens were tested at the laboratories of the School of Civil, Mining and Environmental Engineering at the University of Wollongong, Australia.

\section{Design of Specimens}

Short RC specimens were cast and tested in this study. Each specimen had a square cross section with a side dimension of $200 \mathrm{~mm}$ and a height of $800 \mathrm{~mm}$. Short columns were designed to avoid the formation of secondary moments due to the slenderness effect. Moreover, the dimensions were chosen to be adaptable with the condition and capacity of the available testing machine in the laboratory. The four corners of the specimens were rounded for the purpose of avoiding premature failure and to prepare sufficient effect of confinement of the columns (Wang and Wu 2008; Mirmiran et al. 1998). The concrete cover was $20 \mathrm{~mm}$ on each side of the specimen and at top and bottom as well. A corner radius of $34 \mathrm{~mm}$ was applied to the specimens. The longitudinal and transversal reinforcement of the specimens was designed in accordance with AS3600-2009 (Standards Australia 2009). All specimens were designed inadequately as their internal steel reinforcement ratio was around the lowest ratio of that specified by the standard. The purpose of this design was to produce the condition of an old column that has deteriorated and needs to be strengthened. In addition, the shear reinforcement provided was also at the minimum shear reinforcement required by the design standard $\left(A_{s v \text {. min }}\right)$. Therefore, the specimens had four N12 (12 mm diameter deformed bars) as longitudinal steel reinforcement and $\mathrm{R} 8$ ( $8 \mathrm{~mm}$ diameter plain bars) spaced at $100 \mathrm{~mm}$ as transverse steel reinforcement (ties). The R8 ties spaced at $50 \mathrm{~mm}$ were applied at both ends of the specimens to prevent premature failure at the locations. Fig. 1 shows the details of the reinforcement.

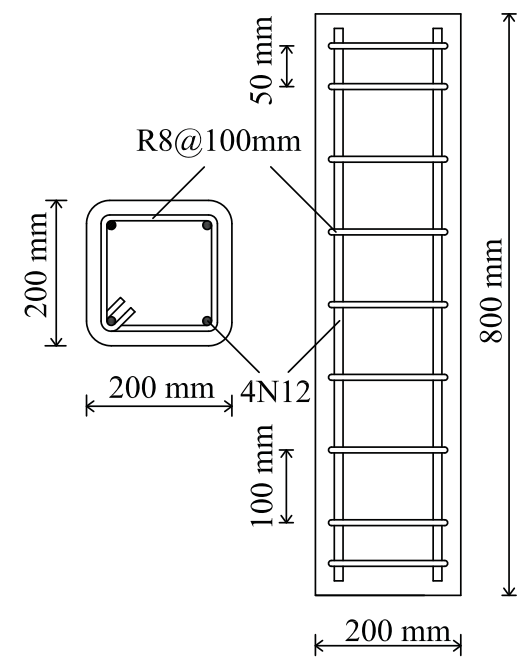

Fig. 1. Details of specimen reinforcement
The general properties of the specimens are shown in Table 1. The specimens were divided into four groups: unwrapped, wrapped with one layer of CFRP, wrapped with three layers of CFRP, and wrapped with one layer of vertical (along specimen axis) CFRP straps and two layers of horizontal (transverse) CFRP. Each group consisted of four specimens; one specimen was tested concentrically, one was tested under a $25 \mathrm{~mm}$ eccentric load, one was tested under $50 \mathrm{~mm}$ eccentric load, and the final one was tested under flexural load. The label used for the specimens was composed of a combination of numbers and letters. The numbers $0,1,2$, and 3 denote the number of CFRP layers. The letters $\mathrm{H}$ and $\mathrm{V}$ denote the orientation of the CFRP: horizontal and vertical, respectively. The letters $\mathrm{C}$ and $\mathrm{B}$ denote column and beam, respectively. The last numbers, 0,25 , and 50 , denote the eccentricity under which the specimens were tested. For example, Specimen 1V2HC50 had one layer of vertical CFRP straps and two layers of transverse CFRP and tested as a column with a 50-mm eccentricity.

\section{Preliminary Testing}

The concrete of the specimens was ready-mix HSC supplied by a local concrete supplier and had an average 28-day compressive strength of $79.5 \mathrm{MPa}$. The tensile strength tests were conducted on the reinforcing steel bars to determine their tensile strength. Average tensile yield strengths of 564 and $516 \mathrm{MPa}$ were obtained for N12 and R8 reinforcing bars, respectively. For wrapping the specimens, in this study carbon fiber (CFRP) was used that was available in the form of rolls, $100 \mathrm{~m}$ in length and $75 \mathrm{~mm}$ in width. The fiber had a nominal thickness of $0.45 \mathrm{~mm}$. Tensile tests were carried out on three CFRP test coupons of one layer, two layers, and three layers of CFRP. In conducting the tests, specimen loading and strain measurement were performed according to ASTM D 3039-08 (ASTM 2008). The tensile strength, tensile strain, and elastic modulus of the CFRP were found to be $1399 \mathrm{MPa}, 1.86 \%$, and $75.4 \mathrm{GPa}$, respectively. These values were the average values calculated using the actual width of the test coupons and the nominal thickness of the fiber. The nominal thickness for the two and three layers of CFRP was assumed to be equal to $0.90 \mathrm{~mm}$ and $1.35 \mathrm{~mm}$, respectively.

\section{Specimen Preparation}

The specimens were cast in a wooden formwork from one batch of concrete. A slump value of $165 \mathrm{~mm}$ was measured, which means

Table 1. Configuration of Test Specimens

\begin{tabular}{|c|c|c|c|c|c|}
\hline $\begin{array}{l}\text { Test } \\
\text { specimen }\end{array}$ & $\begin{array}{l}\text { Side } \\
\text { width } \\
(\mathrm{mm})\end{array}$ & $\begin{array}{l}\text { Height } \\
(\mathrm{mm})\end{array}$ & $\begin{array}{c}\text { Internal } \\
\text { reinforcement }\end{array}$ & $\begin{array}{c}\text { Number } \\
\text { of FRP } \\
\text { layers }\end{array}$ & $\begin{array}{c}\text { Test } \\
\text { eccentricity } \\
(\mathrm{mm})\end{array}$ \\
\hline $0 \mathrm{CO}$ & 200 & 800 & 4N12 and & None & 0 \\
\hline $0 \mathrm{C} 25$ & & & R8 $100 \mathrm{~mm}$ & & 25 \\
\hline $0 \mathrm{C} 50$ & & & & & 50 \\
\hline OB & & & & & Bending \\
\hline $1 \mathrm{HC} 0$ & 200 & 800 & 4N12 and & 1 layer & 0 \\
\hline $1 \mathrm{HC} 25$ & & & $\mathrm{R} 8100 \mathrm{~mm}$ & & 25 \\
\hline 1HC50 & & & & & 50 \\
\hline $1 \mathrm{HB}$ & & & & & Bending \\
\hline $3 \mathrm{HCO}$ & 200 & 800 & 4N12 and & 3 layers & 0 \\
\hline $3 \mathrm{HC} 25$ & & & R8 $100 \mathrm{~mm}$ & & 25 \\
\hline $3 \mathrm{HC} 50$ & & & & & 50 \\
\hline $3 \mathrm{HB}$ & & & & & Bending \\
\hline $1 \mathrm{~V} 2 \mathrm{HC} 0$ & 200 & 800 & 4N12 and & 2 layers & 0 \\
\hline $1 \mathrm{~V} 2 \mathrm{HC} 25$ & & & $\mathrm{R} 8100 \mathrm{~mm}$ & with & 25 \\
\hline $1 \mathrm{~V} 2 \mathrm{HC} 50$ & & & & 1-layer & 50 \\
\hline 1V2HB & & & & straps & Bending \\
\hline
\end{tabular}


the concrete had proper workability. The concrete was poured into a formwork in three stages; in each stage the concrete was compacted adequately using a vibrator to ensure an even dispersion of concrete. After casting, all the specimens were placed under wet hessian rugs and covered with plastic sheets to maintain their moisture conditions. The specimens and hessian rugs were watered twice a day until the formwork was removed at 14 days after casting. The curing process lasted 28 days.

Surface preparation was done by cleaning and grinding the surface of the specimens. Twelve specimens were wrapped with CFRP using a wet layup technique. A mixture of epoxy resin and hardener at a 5:1 ratio was used as an adhesive. The surface was coated first with epoxy resin then the first CFRP layer in predefined orientation. The layer was saturated with resin before the subsequent layer was applied to ensure a perfect bond between the layers. Similarly, the final layer was also saturated with epoxy resin. The column was wrapped strap by strap in either the transverse or longitudinal direction, with no overlap between straps. An overlap of $100 \mathrm{~mm}$ was applied only at the end of the final layer of each strap in the transverse direction. The wrapped specimens were then placed in room temperature for a minimum of 14 days to allow curing of the epoxy resin.

\section{Specimen Testing}

Twelve specimens were tested as columns under axial compression load, and four specimens were tested as beams under flexural load. The Denison $5000 \mathrm{kN}$ compression testing machine was used to test all the specimens until failure. The column ends were leveled first for compression testing to obtain a uniform distributed load applied to the entire face. For this purpose, both ends of the columns were capped with high-strength plaster. To apply an eccentric load on the column, a loading mechanism (Fig. 2) was designed and a new set of loading heads made with high-strength steel plate (Fig. 3) was manufactured. The loading heads were attached at both ends of the column. The loading heads consisted of two parts: a $25 \mathrm{~mm}$ thick steel plate, called a bottom plate, that had a ball joint, and a square $50 \mathrm{~mm}$ thick steel plate, called an adaptor plate. The bottom plate transferred the load generated by the machine to the adaptor plate through the ball joint, which had a designed eccentricity with the column. Then the adaptor plate exerted the load to the column. For concentric loading, only adaptor plates were used to apply the load.

Two different monitoring systems were used to measure the displacement of the columns. For concentric loading, one LVDT was connected directly to the testing machine to measure the axial displacement of the column during the test. Data read from this LVDT were recorded at the same time as load data were recorded by the testing machine. A second LVDT, a laser LVDT, was also used in addition to the first one for eccentric load to measure the lateral deflection $(\delta)$ of the column. The second LVDT was placed horizontally near the mid-height of the column. When the specimen and the instrumentation were placed in position and initial calibration was done, the compression testing then started. The column was tested under displacement control with a loading rate of $0.5 \mathrm{~mm} / \mathrm{min}$, and the end point position was set at $50 \mathrm{~mm}$. A photo of a typical compression testing is shown in Fig. 4.

As mentioned previously, four specimens were tested as beams under flexural loading with a span of $700 \mathrm{~mm}$. Pure bending was applied to the specimens by means of a four-point loading to determine the flexural capacity of the specimens without axial load. Two rigs, top and bottom, were used to exert the load generated by the Denison compression testing machine to the beam specimens. The bottom rig was placed diagonally on the bottom plate (loading

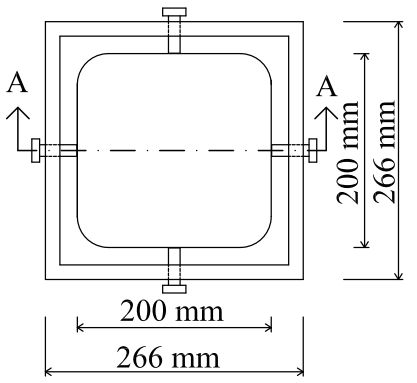

(a)

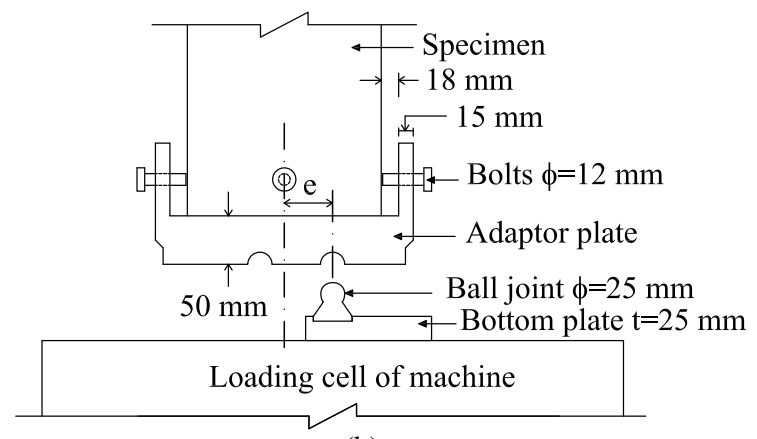

(b)

Fig. 2. Developed eccentric loading mechanism: (a) plan view; (b) Section A-A

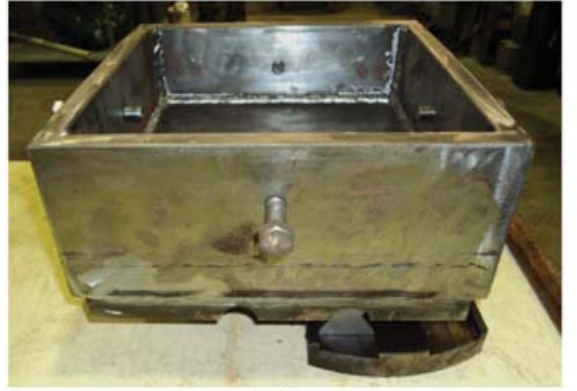

(a)

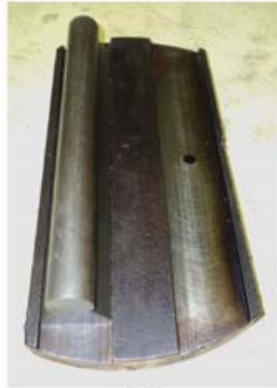

(b)
Fig. 3. Loading head: (a) adaptor plate; (b) bottom plate with ball joint
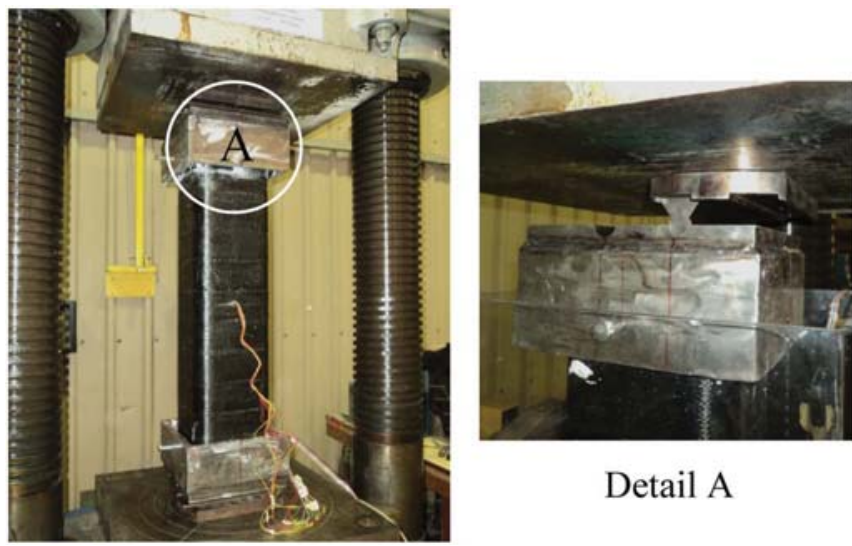

Detail A

Fig. 4. Typical compression testing setup 


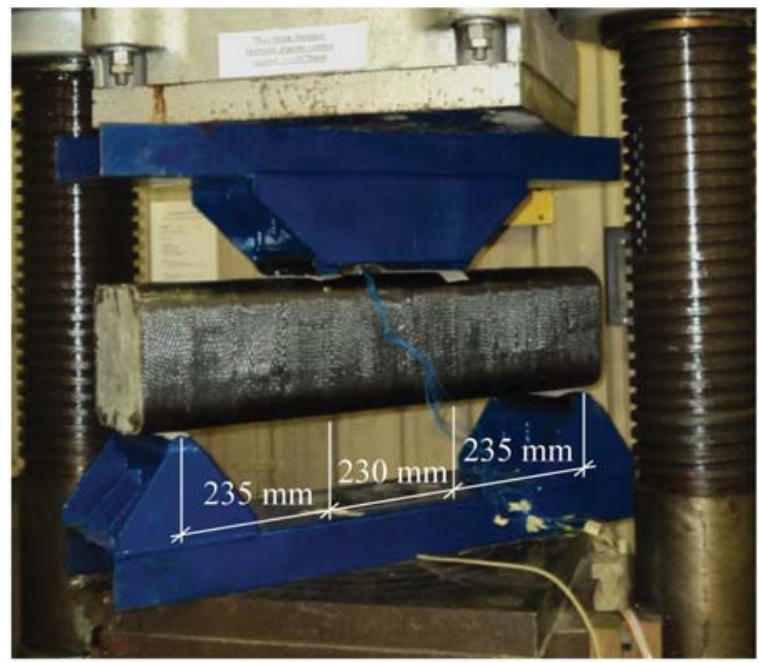

Fig. 5. Typical flexural testing setup

cell) of the machine, and the beam specimen was then placed on the rig. The typical setup of flexural testing of the beams is shown in Fig. 5. The testing machine recorded the applied load simultaneously during the test. A laser LVDT that was placed vertically underneath the bottom rig shot the beam through the provided slot to measure the midspan deflection of the beam during the test. The beam was tested under displacement control, the end point position was set at $50 \mathrm{~mm}$, and the loading rate was set at $0.3 \mathrm{~mm} / \mathrm{min}$.

\section{Experimental Results and Analysis}

\section{Column Failure Modes}

All column specimens were tested to failure. The failure of columns without CFRP wrapping was generally marked by sudden loss of concrete cover, followed by the buckling outward of the longitudinal reinforcement and the rupture of the ties. The failure occurred near the mid-height of the columns. Meanwhile, the failure of the columns wrapped with CFRP was initiated by the appearance of FRP ripples at some places on the column sides, followed by a snapping sound when the load approached the maximum load. A strap-by-strap rupture of the FRP was subsequently observed. The first rupture of CFRP occurred at the maximum load, resulting in a decrease in the load. The columns continued supporting the load until the rupture of the other CFRP while experiencing a large displacement. The rupture of the CFRP and debonding between the CFRP layer and the concrete in the column test revealed the concrete expansion at the place where the CFRP failed. The CFRP rupture occurred at the corner of the column. Buckling of longitudinal reinforcement and crushing of concrete in compression were also observed. Typical failure of unwrapped and wrapped columns under concentric and eccentric loading is shown in Figs. 6 and 7, respectively.

\section{Behavior of Columns}

The ultimate load and corresponding axial and lateral displacements were recorded during the compression testing; the results are summarized in Table 2. Two methods were used to calculate the ductility of the specimens. The first method used the ratio of axial displacement at ultimate load to the axial displacement at yield load. The second method used the ratio of area under

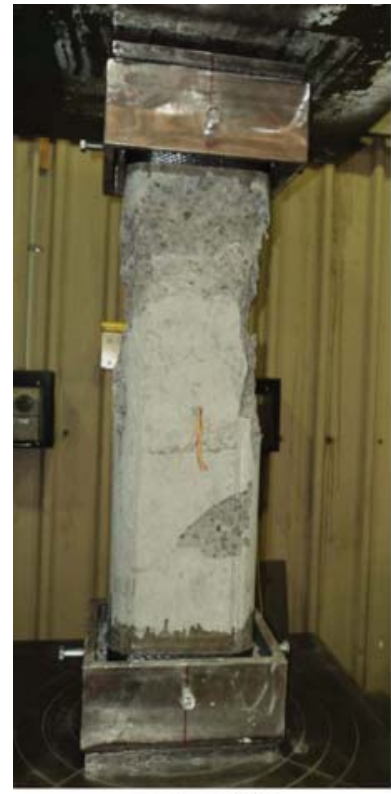

Concentric

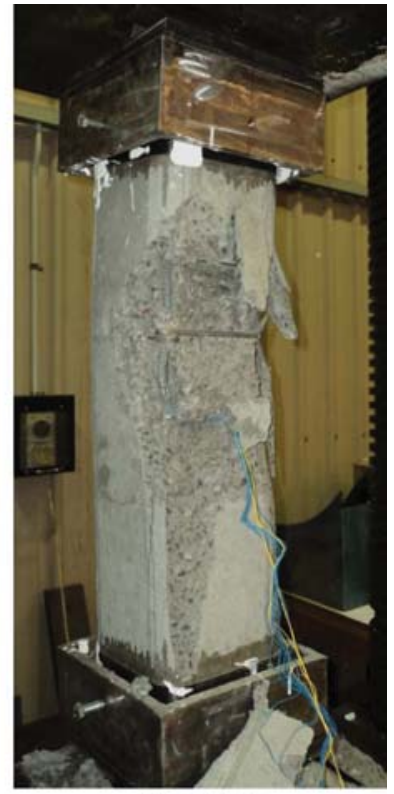

Eccentric
Fig. 6. Typical failure of unwrapped columns

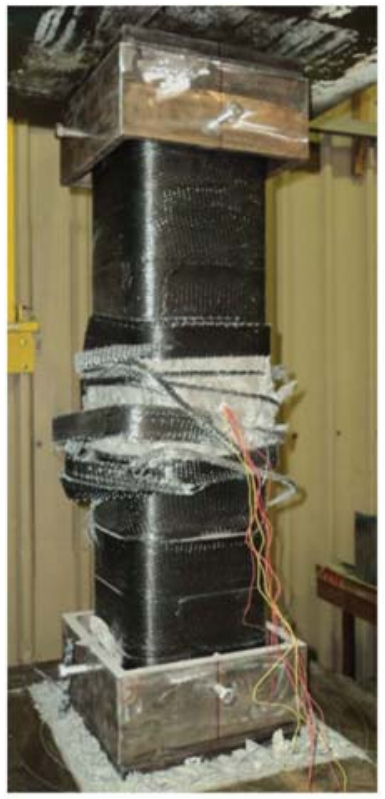

Concentric

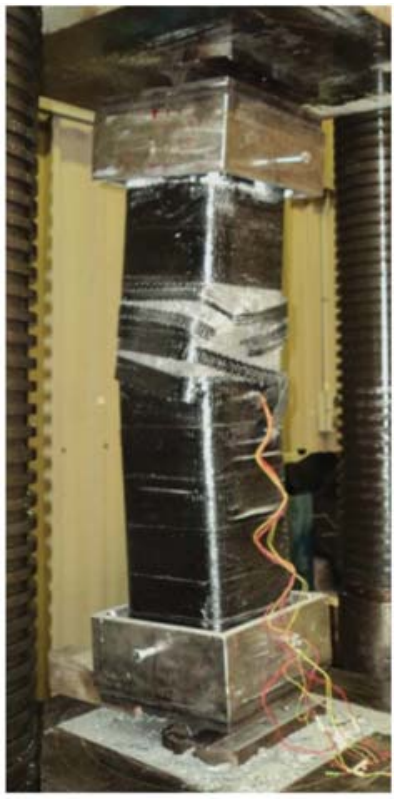

Eccentric
Fig. 7. Typical failure of wrapped columns

the load-axial displacement curve up to the ultimate displacement to the area under the curve up to the yield load. The yield load was assumed to be the load corresponding to an approximation of the limit of the elastic behavior. The ultimate displacement was assumed to be the displacement at $85 \%$ of the maximum load (GangaRao et al. 2007).

Fig. 8 shows the load-displacement curves for concentric columns. The columns had a similar behavior before reaching the maximum load. It is clear that the biggest maximum load and maximum axial displacement among the four columns was achieved by wrapping the column with three layers of CFRP. The maximum load did not increase significantly with the CFRP 
Table 2. Column Test Results

\begin{tabular}{|c|c|c|c|c|c|c|c|c|}
\hline \multirow{2}{*}{$\begin{array}{l}\text { Test } \\
\text { specimen }\end{array}$} & \multirow{2}{*}{$\begin{array}{l}\text { Ultimate } \\
\text { load }(\mathrm{kN})\end{array}$} & \multicolumn{2}{|c|}{$\begin{array}{c}\text { Displacement at } \\
\text { ultimate load }(\mathrm{mm})\end{array}$} & \multicolumn{3}{|c|}{ Axial displacement (mm) } & \multicolumn{2}{|c|}{ Ductility } \\
\hline & & Axial & Lateral & At yield & At $85 \%$ ultimate load & Maximum & Method $1^{\mathrm{a}}$ & Method $2^{\mathrm{a}}$ \\
\hline $0 \mathrm{CO}$ & 3,248 & 4.58 & - & 3.21 & 4.71 & 5.20 & 1.47 & 2.09 \\
\hline $1 \mathrm{HC} 0$ & 3,279 & 4.53 & - & 3.20 & 4.75 & 13.88 & 1.48 & 2.18 \\
\hline $1 \mathrm{~V} 2 \mathrm{HC} 0$ & 3,522 & 5.00 & - & 3.57 & 8.57 & 19.57 & 2.40 & 4.39 \\
\hline $3 \mathrm{HCO}$ & 3,585 & 5.29 & - & 3.63 & 13.47 & 18.51 & 3.71 & 7.16 \\
\hline $0 \mathrm{C} 25$ & 1,950 & 3.91 & 1.87 & 2.93 & 4.12 & 6.25 & 1.41 & 1.87 \\
\hline $1 \mathrm{HC} 25$ & 2,076 & 4.45 & 2.25 & 3.11 & 5.07 & 9.90 & 1.63 & 2.68 \\
\hline $1 \mathrm{~V} 2 \mathrm{HC} 25$ & 2,296 & 4.76 & 2.44 & 3.19 & 8.30 & 15.94 & 2.60 & 5.17 \\
\hline $3 \mathrm{HC} 25$ & 2,269 & 4.48 & 2.11 & 3.18 & 11.17 & 14.95 & 3.52 & 7.45 \\
\hline 0С50 & 1,336 & 3.86 & 2.65 & 2.93 & 4.01 & 4.66 & 1.37 & 1.90 \\
\hline $1 \mathrm{HC} 50$ & 1,433 & 4.05 & 2.32 & 3.02 & 4.98 & 13.20 & 1.65 & 2.84 \\
\hline 1V2HC50 & 1,533 & 3.99 & 2.52 & 2.88 & 9.22 & 14.55 & 3.20 & 7.06 \\
\hline $3 \mathrm{HC} 50$ & 1,534 & 3.99 & 3.19 & 2.89 & 6.64 & 13.09 & 2.30 & 4.66 \\
\hline
\end{tabular}

"Refer to the section "Behavior of Columns" for a definition of the methods.

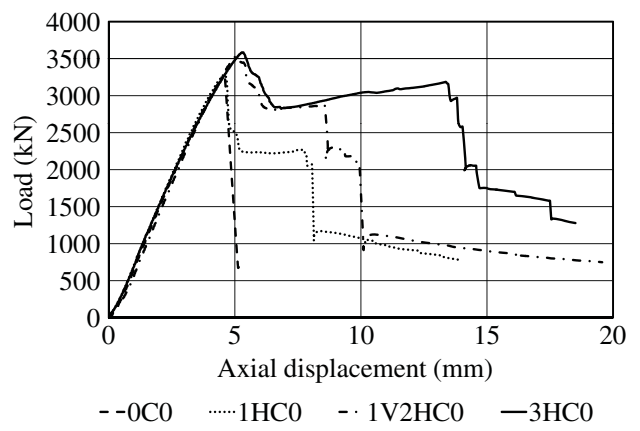

Fig. 8. Load-displacement curves for columns tested under concentric loading

wrapping. However, wrapping columns with CFRP enhanced the performance of the columns by increasing their displacement at failure, meaning more ductility. Increases in the maximum load of $1,8.4$, and $10.4 \%$ relative to the unwrapped column were achieved for Columns $1 \mathrm{HC}, 1 \mathrm{~V} 2 \mathrm{HC} 0$, and $3 \mathrm{HC}$, respectively. This insignificant increase in strength was obtained due to the use of HSC, where in nature HSC is brittle. When approaching the ultimate load, only a small number of microcracks developed in the concrete and the failure occurred suddenly with the appearance of a big crack.

The axial and lateral displacements versus the applied load curves for columns tested under $25 \mathrm{~mm}$ eccentric load are shown in Fig. 9. All columns failed in compression. FRP rupture occurred in all wrapped columns before failure. Column 1HC25 had 6.5\% higher maximum load than the unwrapped column. Increases in maximum load of 17.8 and $16.4 \%$ were achieved for Columns 1V2HC25 and 3HC25, respectively. However, Column 3HC25 showed a better performance than Column 1V2HC25 by having a higher ductility (Table 2). Theoretically, Column 3HC25 should have had a higher maximum load than Column 1V2HC25. The presence of vertical straps that were bonded first to the concrete and then wrapped with two layers of CFRP also contributed to the confinement effect. Similarly, in concentric columns, Column $1 \mathrm{HC} 0$ had only a $1 \%$ higher maximum load than Column $0 \mathrm{C} 0$, whereas Column $3 \mathrm{HC} 0$ had a $2 \%$ higher maximum load than Column 1V2HC0.

Fig. 10 shows the axial and lateral displacements versus the applied load curves for columns tested under $50 \mathrm{~mm}$ eccentric load. Failure in compression was also observed in all columns with

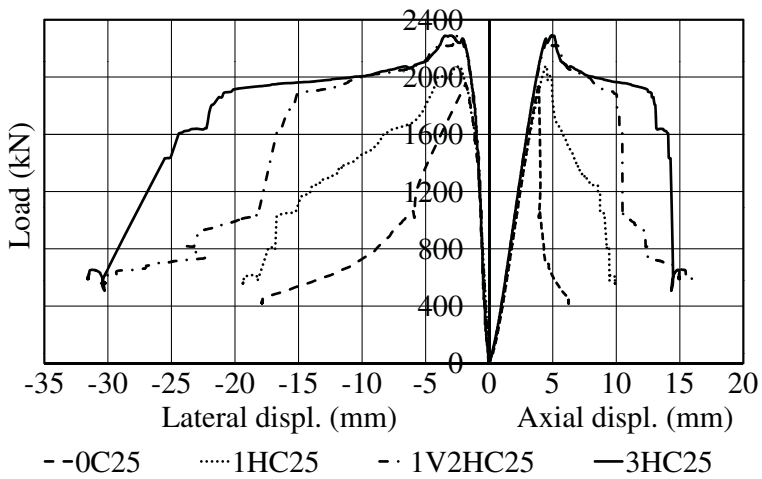

Fig. 9. Load-displacement curves for columns tested under 25-mm eccentricity

cracks in the tension face near the mid-height of the columns. FRP rupture occurred after the maximum load was reached, followed by an increase in displacement. Column 1HC50 had $7.3 \%$ increase in maximum load and a better performance than the unwrapped column. A similar increase in maximum load of $14.8 \%$ was achieved for Columns 1V2HC50 and 3HC50. Column $1 \mathrm{~V} 2 \mathrm{HC} 50$ had a higher ductility than Column 3HC50 (Table 2).

Tests of the 12 column specimens revealed an increase in the maximum load of the columns resulting from wrapping columns with CFRP. An important advantage was achieved: all the wrapped columns showed a better performance than the unwrapped columns, as indicated by their ductility. From the load-displacement

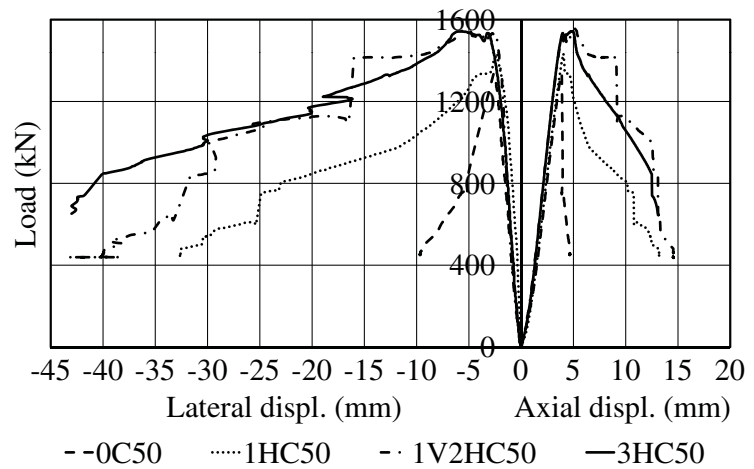

Fig. 10. Load-displacement curves for columns tested under 50-mm eccentricity 

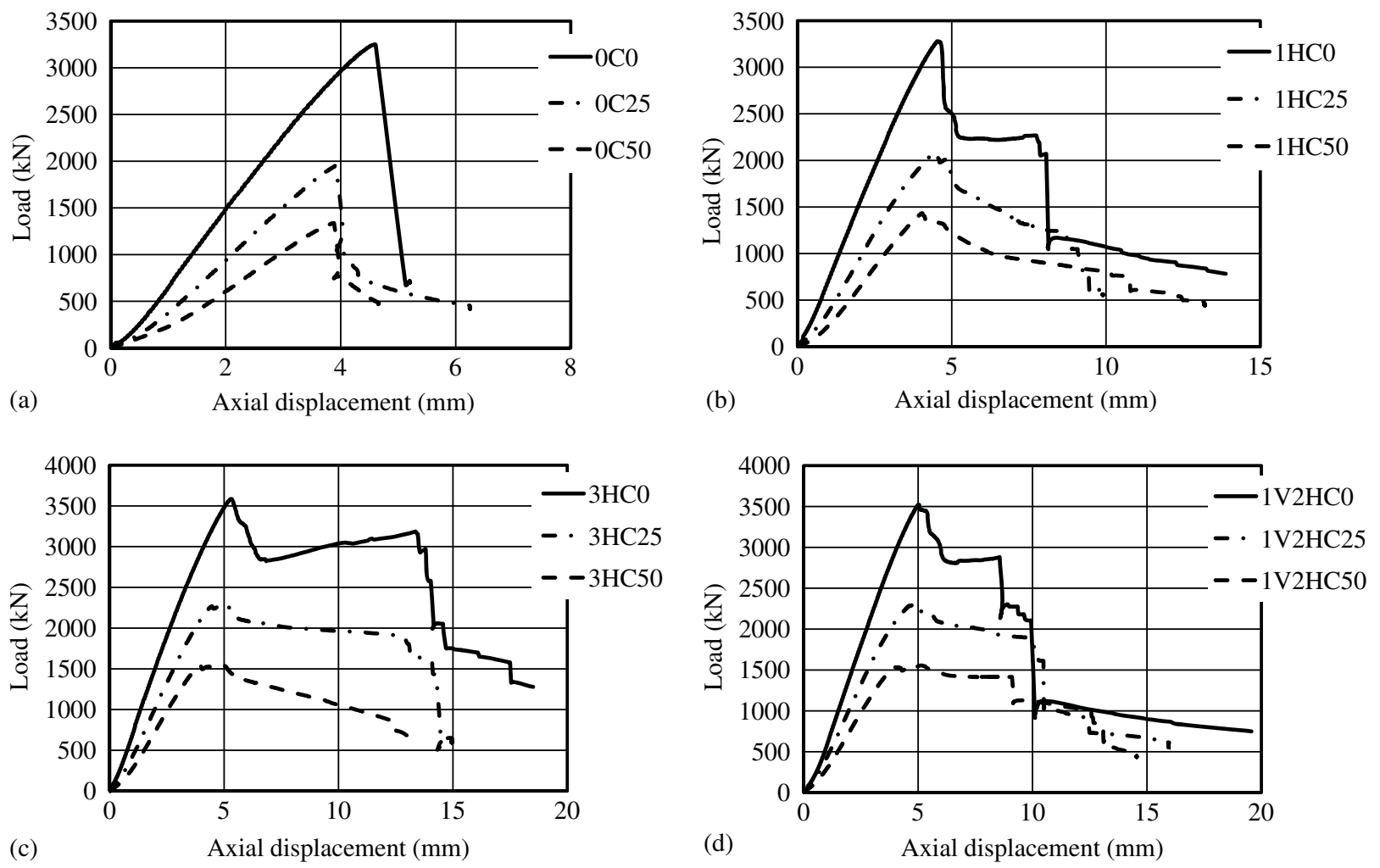

Fig. 11. Load-displacement curves of columns with different eccentricities

curves of the columns, it can be seen that the displacement increased with increasing load until the maximum load was approached. Then, for unwrapped columns the load suddenly dropped with loss of concrete cover. For wrapped columns, the first CFRP rupture occurred when the maximum load was reached, followed by a decrease in load and a sharp increase in displacement. At this stage, the effect of confinement was active to the controlling of the column behavior. Some CFRP rupture still occurred until the column failed. Rupture of longitudinal straps was also observed in the columns wrapped longitudinally with CFRP straps.

\section{Influence of Eccentricity}

To describe the influence of eccentricity on the behavior of the columns, load-displacement curves of the 12 columns in relation to the eccentricity were plotted as shown in Fig. 11. It can be clearly seen that the eccentricity of loading reduced the load carrying capacity and performance of the columns.

\section{Behavior of Beams}

All beams were tested to failure. Fig. 12 shows the load-midspan deflection of the beams tested under flexure. It can be seen that wrapping the beam in the hoop direction with CFRP did not improve significantly the load carrying capacity and performance of the beam under flexural loading. However, the presence of CFRP straps applied longitudinally in Beam 1V2HB showed a large improvement in its load carrying capacity compared to the other beams. As in columns with vertical straps, a consequent strapby-strap rupture of the longitudinal strap was also observed in beam $1 \mathrm{~V} 2 \mathrm{HB}$. The first rupture of the strap resulted in a sudden decrease in load, and then the beam still resisted the load under increasing displacement until the second peak load was reached. The next rupture of the strap resulted in a drop of load. Several ruptures of the

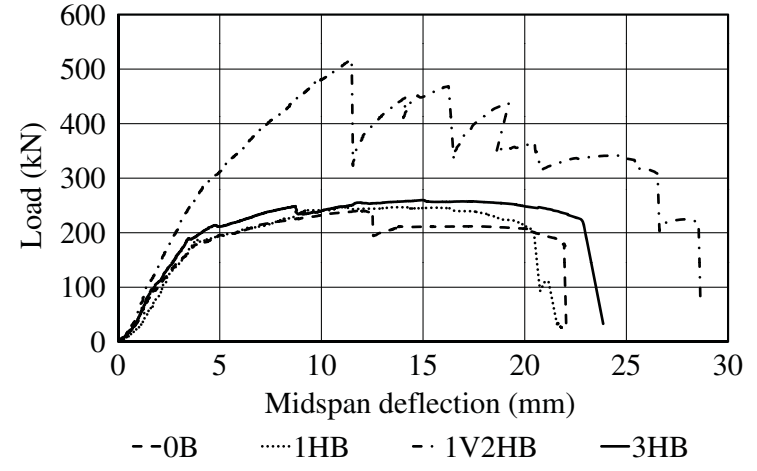

Fig. 12. Load-midspan deflection curves of beams tested under flexural loading

straps occurred until the beam failed (Fig. 12). Yielding of the tensile reinforcing bars was observed in all beams. Table 3 summarizes the analysis results of the beams. It can be seen that Beam 1V2HB had the highest load and ductility of the four beams. Wrapping a beam in the hoop direction with one layer of CFRP had no influence on beam ductility. However, wrapping with three layers of CFRP increased beam ductility slightly. Calculations of beam ductility were done using methods similar to those used for columns.

\section{Axial Load-Bending Moment Interaction Diagrams of Columns}

Axial load-bending moment interaction diagrams were constructed to describe the axial load and bending moment capacity of the columns tested in this study. Any point on the diagrams may represent 
Table 3. Beam Test Results

\begin{tabular}{|c|c|c|c|c|}
\hline Test specimen & OB & $1 \mathrm{HB}$ & 1V2HB & $3 \mathrm{HB}$ \\
\hline Ultimate load (kN) & 241 & 247 & 518 & 260 \\
\hline Deflection at ultimate load (mm) & 11.94 & 11.03 & 11.85 & 14.95 \\
\hline Yield deflectio & 4.06 & 4.20 & 4.15 & 3.89 \\
\hline Maximum deflection (mm) & 20.33 & 20.24 & 25.47 & 22.78 \\
\hline Ductility, Method $1^{\mathrm{a}}$ & 5.01 & 4.82 & 6.13 & 5.86 \\
\hline Ductility, Method $2^{\mathrm{a}}$ & 9.74 & 10.41 & 15.12 & 12.50 \\
\hline
\end{tabular}

"Refer to the section "Behavior of Columns" for a definition of the methods.

a condition of a column under a concentric load, an eccentric load, or a pure bending. The procedure described in Warner et al. (2007) for developing the interaction diagram of conventional RC columns was followed. Full details are given in Warner et al. (2007). The analysis to construct the interaction diagram of an FRP-confined $\mathrm{RC}$ column was carried out based on principles of equilibrium and strain compatibility applied to a conventional RC column. The only difference in the analysis of confined column was the use of an FRP-confined stress-strain curve to replace the stressstrain curve of unconfined concrete. The stress-strain curve of confined concrete proposed by Teng et al. (2002) was adopted here. The model is divided into two portions. The first portion is the ascending branch of the curve from zero stress to stress equal to $f_{c}^{\prime}$, which describes the stress-strain relationship of unconfined concrete. In the second portion, the stress beyond $f_{c}^{\prime}$, the concrete stress increases linearly until reaching the stress of the confined concrete $\left(f_{c c}^{\prime}\right)$ with the corresponding confined-concrete strain $\left(\varepsilon_{c c}^{\prime}\right)$. The second portion describes the stress-strain relationship of confined concrete.

In developing axial load-bending moment interaction diagrams, the axial load and the bending moment were calculated first. The axial concentric load capacity of an unconfined RC column $\left(N_{u o}\right)$ was calculated using the following formula (Warner et al. 2007):

$$
N_{u o}=\alpha_{1} f_{c}^{\prime} A_{g}+f_{s y} A_{s}
$$

where $f_{c}^{\prime}=$ compressive strength of the unconfined concrete; $A_{g}=$ cross-sectional area of column; $f_{s y}=$ yield strength of longitudinal steel reinforcement; and $A_{s}=$ total cross-sectional area of longitudinal steel reinforcement. Because theoretical values were used to develop the interaction $N-M$ diagrams (which were really design diagrams), the factor $\alpha_{1}$ was used, as recommended by Australian standard AS3600-2009 (Standards Australia 2009). The standard provides a value of $\alpha_{1}=1.0-0.003 f_{c}^{\prime}$ within the limits $0.72 \leq \alpha_{1} \leq 0.85$. The value of $\alpha_{1}$ for concrete with compressive strength up to $50 \mathrm{MPa}$ is 0.85 , which is similar to that recommended by ACI318-2008 [American Concrete Institute (ACI) 2008]. The value of $\alpha_{1}$ used in the axial load calculation for the case of wrapped columns was different than that used for unwrapped columns. For unwrapped columns (Column 0C0) with a compressive strength of $79.5 \mathrm{MPa}$, the value of $\alpha_{1}$ is 0.762 . Meanwhile, for wrapped columns, i.e., Columns $1 \mathrm{HC} 0,3 \mathrm{HC} 0$, and $1 \mathrm{~V} 2 \mathrm{HC} 0$, with compressive strength as shown in Table 4, the corresponding values of $\alpha_{1}$ are $0.734,0.72$, and 0.72 , respectively. A minimum value of $\alpha_{1}$ was used for Columns $3 \mathrm{HC} 0$ and $1 \mathrm{~V} 2 \mathrm{HC} 0$.

When an FRP-wrapped concrete column is subjected to compression, FRP confinement resists the expansion of the concrete core. Thus, the FRP is subjected to tension in the hoop direction. For a circular column, the lateral confining pressure is uniformly distributed and can be calculated as follows (Lam and Teng 2002):
Table 4. Compressive Strength of Wrapped Concrete Columns

\begin{tabular}{lccc}
\hline & \multicolumn{2}{c}{ Compressive Strength, $f_{c c}^{\prime}(\mathrm{MPa})$} & \\
\cline { 2 - 3 } Columns & $\begin{array}{c}\text { Theoretical } \\
\left(f_{c c . \text { the }}^{\prime}\right)^{\mathrm{a}}\end{array}$ & $\begin{array}{c}\text { Experimental } \\
\left(f_{c c . \exp }^{\prime}\right)\end{array}$ & $\begin{array}{c}\text { Difference } \\
(\%)\end{array}$ \\
\hline 1HC0 & 88.8 & 105.6 & 15.9 \\
$3 \mathrm{HCO}$ & 107.3 & 118.6 & 9.5 \\
$1 \mathrm{~V} 2 \mathrm{HC} 0$ & 98.0 & 116.3 & 15.7 \\
\hline
\end{tabular}

${ }^{\mathrm{a} C a l c u l a t e d ~ u s i n g ~ E q . ~(4) . ~}$

$$
f_{l}=\frac{2 f_{\text {frp }} t_{\text {frp }}}{d}
$$

where $f_{l}=$ lateral confining pressure; $f_{\text {frp }}=$ tensile strength of FRP in hoop direction; $t_{\text {frp }}=$ total thickness of FRP; and $d=$ diameter of confined concrete.

The following formula, proposed by Richart et al. (1928), has been used by many researchers for predicting the compressive strength of FRP-confined circular concrete columns (Lam and Teng 2002):

$$
\frac{f_{c c}^{\prime}}{f_{c}^{\prime}}=1+k_{1} \frac{f_{l}}{f_{c}^{\prime}}
$$

where $f_{c c}^{\prime}=$ the compressive strength of the confined concrete and $k_{1}=$ the confinement effectiveness coefficient.

FRP-wrapped rectangular concrete columns have a different response than FRP-wrapped circular concrete columns, where the concrete is not uniformly confined by the FRP jacket. The nonuniformity of confinement reduces the confinement effectiveness of the FRP, and, furthermore, the compressive strength of confined concrete varies over a given section (Mirmiran et al. 1998). To predict the confined concrete strength of rectangular column, the shape factor $\left(k_{s}\right)$ is taken into account to consider the effect of nonuniformity of confinement. Thus, Eq. (3) is modified by Teng et al. (2002) as follows:

$$
\frac{f_{c c}^{\prime}}{f_{c}^{\prime}}=1+k_{1} k_{s} \frac{f_{l}}{f_{c}^{\prime}}
$$

\begin{tabular}{|c|c|c|c|c|}
\hline Specimen & $\begin{array}{c}\text { Maximum } \\
\text { load, } \\
N_{\max }(\mathrm{kN})\end{array}$ & $\begin{array}{c}\text { Deflection } \\
\text { at maximum } \\
\text { load, } \\
\delta(\mathrm{mm})\end{array}$ & $\begin{array}{c}M_{1}=N_{\max } e \\
(\mathrm{kN}-\mathrm{m})\end{array}$ & $\begin{aligned} M_{2}= & N_{\max }(e+\delta) \\
& (\mathrm{kN}-\mathrm{m})\end{aligned}$ \\
\hline $0 \mathrm{C} 0$ & 3,248 & 0 & 0 & 0 \\
\hline $0 \mathrm{C} 25$ & 1,950 & 1.87 & 48.75 & 52.39 \\
\hline $0 \mathrm{C} 50$ & 1,336 & 2.65 & 66.80 & 70.33 \\
\hline OB & 241 & 11.94 & $28.30^{\mathrm{a}}$ & $28.30^{\mathrm{a}}$ \\
\hline $1 \mathrm{HC} 0$ & 3,279 & 0 & 0 & 0 \\
\hline $1 \mathrm{HC} 25$ & 2,076 & 2.25 & 51.90 & 56.58 \\
\hline 1HC50 & 1,433 & 2.32 & 71.65 & 74.97 \\
\hline $1 \mathrm{HB}$ & 247 & 11.03 & $29.01^{\mathrm{a}}$ & $29.01^{\mathrm{a}}$ \\
\hline $3 \mathrm{HCO}$ & 3,585 & 0 & 0 & 0 \\
\hline $3 \mathrm{HC} 25$ & 2,269 & 2.11 & 56.73 & 61.52 \\
\hline $3 \mathrm{HC} 50$ & 1,534 & 3.19 & 76.70 & 81.60 \\
\hline $3 \mathrm{HB}$ & 260 & 14.95 & $30.52^{\mathrm{a}}$ & $30.52^{\mathrm{a}}$ \\
\hline 1V2HC0 & 3,522 & 0 & 0 & 0 \\
\hline 1V2HC25 & 2,296 & 2.44 & 57.40 & 63.01 \\
\hline 1V2HC50 & 1,533 & 2.52 & 76.65 & 80.51 \\
\hline 1V2HB & 518 & 11.85 & $60.87^{\mathrm{a}}$ & $60.87^{\mathrm{a}}$ \\
\hline
\end{tabular}

Table 5. Experimental Bending Moment Capacity of Columns

${ }^{\mathrm{a} C a l c u l a t e d ~ u s i n g ~ E q . ~(10) . ~}$ 


$$
k_{s}=\left(\frac{b}{h}\right) \frac{A_{e}}{A_{c}}
$$

$$
\frac{A_{e}}{A_{c}}=\frac{1-\left[(b / h)\left(h-2 R_{c}\right)^{2}+(h / b)\left(b-2 R_{c}\right)^{2}\right] /\left(3 A_{g}\right)-\rho_{s c}}{1-\rho_{s c}}
$$

$$
A_{g}=b h-(4-\pi) R_{c}^{2}
$$

where $b$ and $h=$ width and height of column section, respectively (in the case of a square section, $b=h$ ); $A_{e}=$ effective confinement

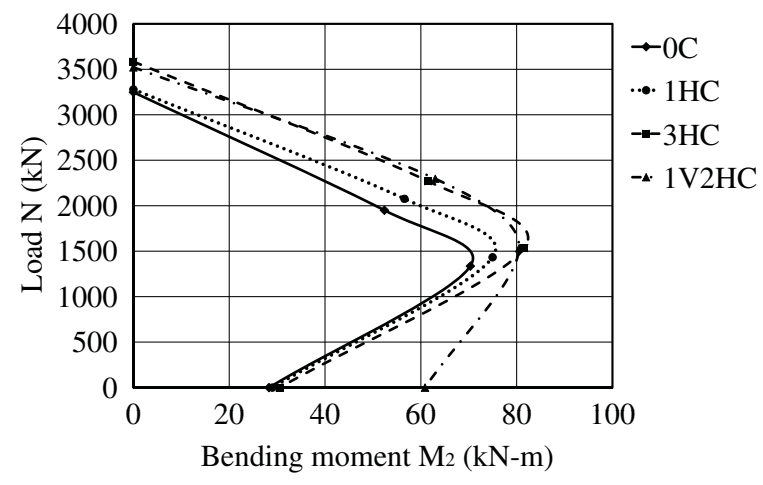

Fig. 13. Experimental N-M diagram of columns
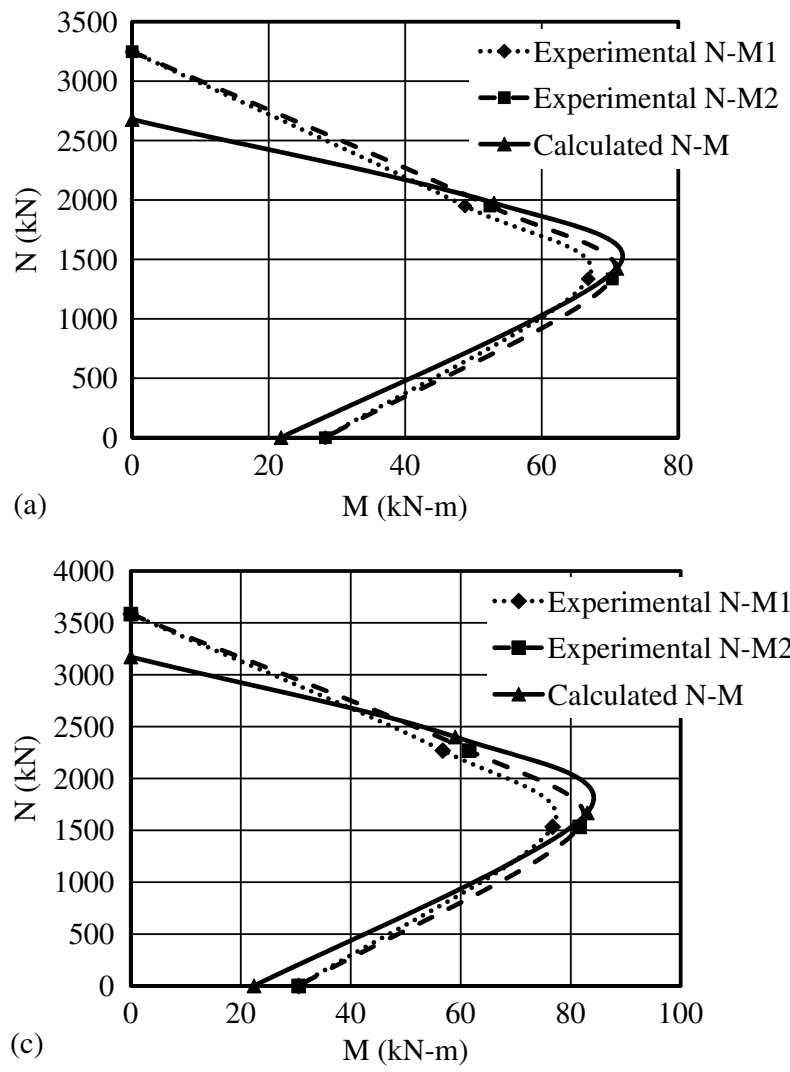

area; $A_{c}=$ total area of concrete; $R_{c}=$ corner radius; and $\rho_{s c}=$ cross-sectional area ratio of longitudinal steel. A value of $k_{1}=2.98$ was proposed for predicting the strength of FRPconfined concrete columns having a rectangular or square cross section. $f_{l}$ in Eq. (4) becomes an equivalent confining pressure that is interpreted as the confining pressure provided by the FRP jacket to an equivalent circular column (with the diagonal length $D$ ) and proposed as follows:

$$
f_{l}=\frac{2 f_{\text {frp }} t_{\text {frp }}}{D}=\frac{2 f_{\text {frp }} t_{\text {frp }}}{\sqrt{h^{2}+b^{2}}}
$$

The theoretical compressive strengths of the CFRP-wrapped columns investigated in this study are presented in Table 4 and compared with the experimental results. The 28-day concrete compressive strength was taken as the unconfined concrete compressive strength to calculate the compressive strength of the confined concrete. It can be seen that the confined compressive strength obtained from the theoretical results were 15.9, 9.5, and $15.7 \%$ smaller than that obtained from the experimental results for Columns $1 \mathrm{HC} 0,3 \mathrm{HC} 0$, and $1 \mathrm{~V} 2 \mathrm{HC} 0$, respectively. Since the compressive strengths of the CFRP-wrapped columns were obtained, the axial concentric load capacity of the wrapped column $\left(N_{u c}\right)$ were calculated using Eq. (1) by replacing $f_{c}^{\prime}$ with $f_{c c}^{\prime}$, as formulated in Eq. (4). As a comparison, another strength model, proposed by $\mathrm{Wu}$ and Wang (2009), was used to predict the strength of confined columns. Values of $f_{c c}^{\prime} / f_{c}^{\prime}$ of $1.089,1.173$, and 1.255 for Columns $1 \mathrm{HC}, 1 \mathrm{~V} 2 \mathrm{HC}$, and $3 \mathrm{HC}$, respectively, were obtained, which were smaller than those calculated using Eq. (4). Eq. (4) yielded values
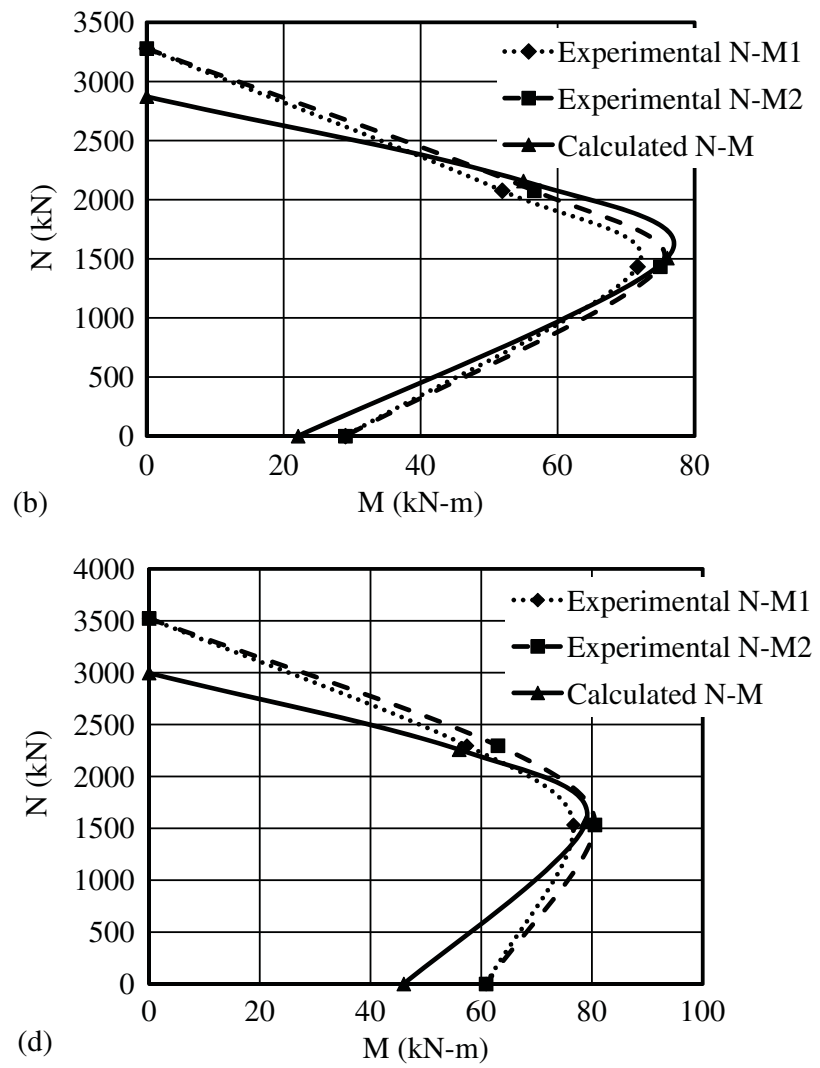

Fig. 14. Experimental and theoretical N-M diagrams of columns 
of $f_{c c}^{\prime} / f_{c}^{\prime}$ of $1.125,1.213$, and 1.355 for the corresponding columns.

The bending moment capacity $(M)$ of the eccentrically loaded columns, including the secondary moments, was calculated by multiplying the maximum load capacity $\left(N_{\max }\right)$ and the sum of eccentricity $(e)$ and lateral deflection $(\delta)$ at the maximum load as follows:

$$
M=N_{\max }(e+\delta)
$$

However, the bending moment capacity of beams was calculated using

$$
M=\frac{P}{2} a
$$

where $P=$ maximum load applied to the specimen with four-point loading apparatus and $a=$ shear span length, or the distance between the support and the closer loading point ( $a=235 \mathrm{~mm}$ in this study).

The bending moment capacity of the investigated columns is reported in Table 5, and the experimental interaction diagram of the columns is shown in Fig. 13. It can be seen that wrapping a column with one layer of CFRP increased slightly the axial load and bending moment capacity of the eccentrically loaded columns. A larger increment than that was obtained in column wrapped with three layers of CFRP and in the columns wrapped with one layer of vertical straps and two layers of CFRP. The only increment in bending moment capacity was obtained in columns that had vertical CFRP straps. The presence of the CFRP straps applied longitudinally contributed an important effect to the bending capacity of the column.

Fig. 14 shows the calculated and experimental interaction diagrams of Columns $0 \mathrm{C}, 1 \mathrm{HC}, 3 \mathrm{HC}$, and $1 \mathrm{~V} 2 \mathrm{HC}$, respectively. It can be seen from those figures that under eccentric loading the calculated interaction diagram gave values that were close to the experimental results. However, the calculated axial loads of all columns under concentric loading were smaller than those of the experimental results.

\section{Conclusions}

A total of 16 square RC specimens with CFRP wrapping were tested in this study to investigate the influence of eccentricity, number of layers, and presence of vertical straps on specimen behavior and load carrying capacity. Twelve columns were tested under compression loading and four beams were tested under flexural loading. Based on the experimental work carried out in this study, the following conclusions were drawn:

1. CFRP wrapping had a more significant effect on the maximum load of eccentrically loaded columns compared to concentrically loaded columns.

2. No significant increase in maximum load was obtained when the columns were wrapped with one layer of CFRP.

3. Increasing the number of the CFRP layers resulted in an increase in the load and the performance of the columns.

4. The CFRP wrapping enhanced the performance of the columns by postponing the rupture of the concrete and reinforcement, which means it increased the column ductility. Similar results were obtained in beams tested in flexure.

5. In columns with a large eccentricity, which means with a large bending moment, the presence of CFRP straps produced higher ductility than in columns wrapped horizontally with a similar number of CFRP layers.
6. Using an existing strength model to estimate the capacity of CFRP column yielded strength magnitudes that were lower than the experimental ones. This observation shows that the model yields good predictions of the strength of CFRPwrapped columns.

7. The theoretical axial load-bending moment interaction diagram shows values that are close to those of the experimental result, except at the point under concentric load.

Finally, the use of longitudinal FRP layers can be recommended in combination with FRP wrapped circumferentially to enhance the performance of columns loaded eccentrically.

\section{References}

American Concrete Institute (ACI). (2008). "Building code requirements for structural concrete and commentary." ACI 318-08, Farmington Hills, MI.

ASTM. (2008). "Standard test method for tensile properties of polymer matrix composite materials." ASTM D 3039-08, Philadelphia.

Bisby, L., and Ranger, M. (2010). "Axial-flexural interaction in circular FRP-confined reinforced concrete columns." Constr. Build. Mater., 24(9), 1672-1681.

Chaallal, O., and Shahawy, M. (2000). "Performance of fiber-reinforced polymer-wrapped reinforced concrete column under combined axial-flexural loading." ACI Struct. J., 97(4), 659-668.

Eid, R., Roy, N., and Paultre, P. (2009). "Normal- and high-strength concrete circular elements wrapped with FRP composites." J. Compos. Constr., 13(2), 113-124.

GangaRao, H. V. S., Taly, N., and Vijay, P. V. (2007). Reinforced concrete design with FRP composites, CRC, London.

Hadi, M. N. S. (2006a). "Behaviour of FRP wrapped normal strength concrete columns under eccentric loading." Compos. Struct., 72(4), 503-511.

Hadi, M. N. S. (2006b). "Comparative study of eccentrically loaded FRP wrapped columns.” Compos. Struct., 74(2), 127-135.

Hadi, M. N. S. (2007a). "Behaviour of FRP strengthened concrete columns under eccentric compression loading." Compos. Struct., 77(1), 92-96.

Hadi, M. N. S. (2007b). "The behaviour of FRP wrapped HSC columns under different eccentric loads." Compos. Struct., 78(4), 560-566.

Kumutha, R., Yaidyanathan, R., and Palanichamy, M. S. (2007). "Behaviour of reinforced concrete rectangular columns strengthened using GFRP." Cem. Concr. Compos., 29(8), 609-615.

Lam, L., and Teng, J. G. (2002). "Strength model for fiber-reinforced plastic-confined concrete.” J. Struct. Eng., 128(5), May, 612-623.

Li, J., and Hadi, M. N. S. (2003). "Behaviour of externally confined high strength concrete columns under eccentric loading." Compos. Struct., 62(2), 145-153.

Maaddawy, T. E. (2009). "Strengthening of eccentrically loaded reinforced concrete columns with fiber-reinforced polymer wrapping system: Experimental investigation and analytical modeling." J. Compos. Constr., 13(1), 13-24.

Mirmiran, A., Shahawy, M., Samaan, M., Echary, H. E., Mastrapa, J. C., and Pico, O. (1998). "Effect of column parameters on FRP-confined concrete." J. Compos. Constr., 2(4), 175-185.

Parvin, A., and Wang, W. (2001). "Behavior of FRP jacketed concrete columns under eccentric loading." J. Compos. Constr., 5(3), 146-152.

Richart, F. E., Brandtzaeg, A., and Brown, R. L. (1928). "A study of the failure of concrete under combined compressive stresses." Bulletin No. 185, Engineering Experimental Station, Univ. of Illinois at UrbanaChampaign, Urbana-Champaign, IL.

Rousakis, T. C., Karabinis, A. I., and Kiousis, P. D. (2007). "FRP-confined concrete members: Axial compression experiments and plasticity modeling." Eng. Struct., 29(7), 1343-1353.

Standards Australia. (2009). "Concrete structures.” AS3600-2009, Sydney, Australia.

Teng, J. G., Chen, J. F., Smith, S. T., and Lam, L. (2002). FRP-strengthened $R C$ structures, Wiley, West Sussex, UK. 
Teng, J. G., and Lam, L. (2004). "Behavior and modeling of fiber reinforced polymer-confined concrete.” J. Struct. Eng., 130(11), 1713-1723.

Wang, L. M., and Wu, Y. F. (2008). "Effect of corner radius on the performance of CFRP-confined square concrete columns: Test." Eng. Struct., 30(2), 493-505.
Warner, R. F., Foster, S. J., and Kilpatrick, A. E. (2007). Reinforced concrete basics: Analysis and design of reinforced concrete structures, Pearson Education, Sydney, Australia.

Wu, Y. F., and Wang, L. M. (2009). "Unified strength model for square and circular concrete columns confined by external jacket." J. Struct. Eng., 135(3), 253-261. 